\title{
Las estrategias publicitarias de los anunciantes españoles en los Social Media El caso de Facebook
}

Advertising strategies of Spanish advertisers in Social Media The Facebook case

Dra. Natalia Abuín Vences Universidad Complutense de Madrid nabuinve@ucm.es
Abuín, N. (2014). Las estrategias publicitarias de los anunciantes españoles en los Social Media. El caso de Facebook. Revista Internacional de Investigación en Comunicación aDResearch ESIC. No 9 Vol 9. Primer semestre, enero-junio 2014. Págs. 64 a 75 DOI: 10.7263/ADRESIC.009.004 
RESUMEN

JEL Classification:

M37

Palabras clave:

Publicidad,

redes sociales,

Facebook,

estrategias publicitarias

En este trabajo se analizan las estrategias de los anunciantes españoles en las redes sociales. El objetivo es conocer el tipo de espacios que estos anunciantes han creado en la red, sus objetivos comerciales y si ofrecen servicios de valor añadido a sus seguidores.

Se ha seleccionado la red social Facebook, por ser la que mayor número de usuarios posee a escala global (más de novecientos millones según las últimas cifras) y se ha llevado a cabo un análisis de contenido de los microsites de los anunciantes españoles que más invierten en publicidad online: Telefónica, Vodafone, El Corte Inglés, Renault y Orange.

Los resultados apuntan a que los grandes anunciantes están apostando por los medios sociales y el éxito de sus estrategias en estos medios radica en la oferta de servicios de valor añadido y promociones exclusivas para los usuarios de sus microsites.

In this paper the strategies of Spanish advertisers in social networks are analysed. The objective is to learn about the type of areas these advertisers have created on the network, their commercial objectives and if they offer value-add services to their followers.

The social network, Facebook, was selected because it has the highest numbers of users globally (more than nine hundred million according to the latest figures)

Clasificación JEL:

M37

Key words:

Advertising,

social networks,

Facebook

advertising strategies and a contents analysis was carried out of the microsites of the Spanish advertisers with the biggest online spend: Telefónica, Vodafone, El Corte Inglés, Renault and Orange.

The results show that the big advertisers are betting on social media and the success of their strategies in this media lies in the value-add services and exclusive promotions offered to their microsite users. 


\section{Introducción}

En los últimos años estamos asistiendo a una gran revolución en la Red, la denominada Web Social, integrada por una serie de espacios como blogs, wikis, comunidades virtuales, redes sociales... que han convertido al usuario en el verdadero protagonista de los medios online.

Este tipo de espacios han provocado un cambio en las relaciones de poder entre los productores y los consumidores de información, que han pasado de ser complementarias a ser simétricas. Antes de la aparición de los Social Media los productores de información controlaban los flujos haciendo llegar a los consumidores aquellos contenidos que consideraban oportunos, ocultado otros que no querían hacer públicos. La llegada de estos medios ha democratizado la tecnología y ha convertido a los usuarios-consumidores en productores y distribuidores de contenidos a escala global.

Este cambio en las relaciones de poder afecta especialmente a los anunciantes, ya que los nuevos usuarios, los denominados consumidores 2.0 tienen un gran poder de prescripción sobre su red de contactos. Las opiniones de los internautas que utilizan los medios sociales tienen mucha influencia sobre el resto de usuarios ya que son vistas como opiniones entre iguales, como consejos que pueden provocar pérdidas millonarias a una empresa en pocas horas debido a otra de las características de estos medios: la viralidad.

Los medios sociales permiten a los usuarios satisfacer sus necesidades de intercomunicación, y así es como definen Solanas et al. la viralidad: como la capacidad o el deseo de las personas de contar a otras las cosas que le pasan, que le gustan o que les disgustan. Estos mensajes virales circulan entre los usuarios a un gran velocidad, en pocas horas pueden haber dado la vuelta al globo. Existen ejemplos de empresas que han perdido cientos de millones a causa de una opinión negativa publicada por uno de sus clientes en los medios sociales.

Los consumidores 2.0 están inmersos en un mercado micromediatizado, formado por millones de espacios con audiencias muy segmentadas y con la posibilidad de compartir información, lo que requiere nuevas estrategias publicitarias que permitan, por una parte, alcanzar a estos públicos hiperfragmentados, y por la otra, convencer a un usuario que maneja mayores cantidades de información que el consumidor convencional.

En este trabajo se lleva a cabo un profundo análisis de las necesidades comunicativas y creativas de la publicidad en la Web 2.0 atendiendo a las características de los espacios que la conforman.

El actual panorama comunicativo online requiere mensajes altamente segmentados, integrados con los contenidos y contextualizados. En cuanto a la estrategia, la única forma de llegar a los usuarios de medios sociales es estar presente en los mismos. Para alcanzar la eficacia publicitaria en medios sociales y conocer la opinión que los internautas tienen de un determinado producto o de una empresa concreta, la mejor estrategia para los anunciantes es crear espacios propios dentro de los medios sociales en los que se muevan sus clientes .

Este estudio forma parte de una serie de investigaciones del Grupo de Investigación FONTA (Formación en Nuevas Tecnologías del Audiovisual) de la Universidad Complutense de Madrid.

\section{Objetivos}

Este trabajo tiene como objetivo analizar las estrategias de los anunciantes en las redes sociales, 
con la finalidad de verificar o refutar las siguientes hipótesis:

H1: El nuevo escenario publicitario obliga a los anunciantes a emplear los medios sociales para alcanzar sus potenciales consumidores: el eje central de la estrategia en social media debe ser la creación y la gestión eficaz de microespacios corporativos en medios sociales.

H2: LPara atraer a sus consumidores y potenciales consumidores a sus espacios dentro de los social media los anunciantes deben ofrecer servicios de valor añadido a través de los mismos.

\section{Metodología}

Para alcanzar los objetivos propuestos al inicio de esta investigación se llevará a cabo un análisis de contenido de los microespacios en Facebook de los anunciantes que más invierten en la red según el Estudio de inversión publicitaria en medios digitales publicado por el Interactive Advertising Boureau en 2011.

En cuanto al medio objeto de estudio, se ha seleccionado la red social Facebook por ser la que mayor número de usuarios posee a escala global: más de ochocientos millones según los últimos datos publicados. Si tenemos en cuenta que en el mundo hay dos mil millones de internautas podemos afirmar que casi uno de cada dos poseen un perfil en este medio social.

Los anunciantes cuyo microsite será sometido a un análisis de contenido serán: Telefonica, Vodafone, El Corte Inglés, Renault y Orange. Tal y como se ha apuntado anteriormente se han seleccionado estos anunciantes por ser los que más invierten en Internet. A este respecto es necesario puntualizar que el quinto y sexto lugar por la cantidad de inversión publicitaria en la red lo ocupan Procter and Gamble y Jazztel, pero no forman parte del corpus de análisis ya que en el momento del análisis no poseían microespacios en Facebook.

\section{Las redes sociales orígenes y evolución}

La idea de las redes sociales en Internet tiene su germen en la Teoría de los Seis Grados de Separación, formulada inicialmente en 1929 por el escritor húngaro Frigyes Karinthy en su obra Chains. Esta teoría postula que el número de conocidos crece exponencialmente con el número de enlaces en la cadena, y sólo un pequeño número de conexiones son necesarias para que el conjunto de conocidos se convierta en la población humana entera.

Según esta teoría, cada persona conoce de media a unos 100 individuos, y si cada uno de ellos se relaciona con otros 100 , cualquiera puede pasar un recado a 10.000 personas tan sólo pidiendo a un amigo que envíe el mensaje a sus contactos. Estos 10.000 serían contactos de segundo nivel, que un individuo no conoce pero a los que puede acceder fácilmente pidiendo a sus amigos y familiares que se los presenten, y a los que se suele recurrir para ocupar un puesto de trabajo o realizar una compra. Cuando preguntamos a nuestros amigos, por ejemplo, si conocen a alguien que esté buscando trabajo porque tenemos un puesto disponible, estamos utilizando estas redes sociales informales, que permiten el funcionamiento de nuestra sociedad.

Si esos 10.000 conocen a otros 100 , la red ya se ampliaría a 1.000.000 de personas conectadas en un tercer nivel, a 100.000.000 en un cuarto nivel, a 10.000.000.000 en un quinto nivel y a 1.000.000.000.000 en un sexto nivel. En seis pasos y con las tecnologías disponibles, se po- 
dría enviar un mensaje a cualquier individuo del planeta. Evidentemente, cuantos más pasos haya que dar, más lejana será la conexión entre dos individuos y más difícil la comunicación.

La World Wide Web, sin embargo, ha eliminado algunas de esas barreras, permitiendo el desarrollo de redes sociales mundiales que posibilitan a sus miembros acceder a los contactos de sus conocidos, y de los conocidos de sus conocidos, permitiéndoles saltarse varios eslabones de esa cadena que postula la Teoría de los Seis Grados de Separación. Esta facilidad para acceder a los perfiles de un importante número de personas está haciendo que se desarrollen redes especializadas, por ejemplo en la búsqueda y oferta de empleo.

En la década de los 50, Ithiel de Sola Pool (MIT) y Manfred Kochen (IBM) publicaron un trabajo titulado Contact and Influence en el que postulaban que todas las personas estaban interconectadas, y se propusieron demostrar esta hipótesis desde la óptica de las matemáticas. Consiguieron formular el problema ("dado un conjunto de $\mathrm{N}$ personas, ¿cual es la probabilidad de que cada miembro de estos $\mathrm{N}$ estén conectados con otro miembro vía k1, k2, k3,..., kn enlaces?"), pero nunca llegaron a resolverlo.

En algún momento de nuestra vida, hemos hecho un viaje y nos hemos encontrado lejos de nuestro hogar con un conocido, o con alguna persona con la que compartíamos algún contacto. Estas situaciones han dado lugar a la frase "el mundo es un pañuelo", y fue esta expresión la que en 1967 permitió al psicólogo estadounidense Stanley Milgram idear una nueva manera de probar la Teoría de los Seis Grados de Separación, a la que él denominó "el problema del pequeño mundo". El experimento consistió en la selección al azar de varias personas del medio oeste de Estados Unidos, para que enviaran tarjetas postales a una persona desconocida situada a varios miles de millas de distancia. Los remitentes conocían el nombre del destinatario, su ocupación y la localización aproximada. Se les indicó que enviaran el paquete a una persona que ellos conocieran y que pensaran que también pudiera conocer de forma directa al destinatario. Esta persona tendría que hacer lo mismo, y así sucesivamente hasta que el paquete fuera entregado al receptor final.

Aunque los participantes esperaban que la cadena incluyera al menos cientos de intermediarios, la entrega de cada paquete requirió de media entre cinco y siete de ellos. Los descubrimientos de Milgram fueron publicados en "Psychology Today" e inspiraron la frase "seis grados de separación". Sin embargo, los hallazgos de Milgram fueron criticados porque estaban basados en el número de paquetes que alcanzaron al destinatario, que fueron sólo alrededor de un tercio del total de paquetes enviados. Los detractores de esta teoría alegaron además que la muestra era parcial y estaba formada por personas con ingresos económicos superiores a la media, lo que habría favorecido la llegada de los paquetes a sus destinatarios. Sin embargo para Milgram, su experimento supuso un gran avance para la investigación en ciencias sociales, pues refuta la idea de la alienación del individuo:

"Aunque el estudio empezó con un conjunto de cuestiones específicas suscitadas por el problema del mundo pequeño, el procedimiento ilumina un conjunto de temas bastante más amplio. Revela una estructura de comunicación potencial cuyas características sociológicas todavía tienen que ser puestas de manifiesto. Cuando entendamos la estructura 
de esta red de comunicación potencial, comprenderemos bastante más sobre la integración de la sociedad en general. Mientras que muchos estudios en las ciencias sociales muestran cómo el individuo está alienado y separado del resto de la sociedad, este estudio demuestra que, en cierto sentido, todos estamos delimitados conjuntamente por un tejido social firmemente urdido" (Milgram, 1967, p. 28).

Los seis grados de separación se convirtieron en una idea aceptada en la cultura popular después de que Brett $C$. Tjaden publicase un juego de ordenador en el sitio Web de la University of Virginia basado en el problema del pequeño mundo. Tjaden usó The Internet Movie Database (IMDb) para documentar las conexiones entre diferentes actores. En este juego, los participantes tenían que encontrar la conexión entre dos actores famosos en menos de seis pasos. La revista Time llamó a su sitio The Oracle of Bacon at Virginia, uno de los "Diez Mejores Sitios Web de 1996". Hoy se siguen empleando programas similares en clases de introducción de Ciencias de la Computación con la finalidad de ilustrar grafos y listas.

Precisamente sobre estas teorías se ha desarrollado la tecnología que ha dado lugar a las redes sociales. Estos espacios son servicios con base Web que permiten a los individuos construir un perfil público o semi-público dentro de un sistema limitado, articular una lista con otros usuarios con los que quieren compartir una conexión, y ver y atravesar su lista de contactos y aquellos hechos por otros miembros del sistema. La naturaleza y la nomenclatura de estas conexiones puede variar mucho de una red a otra (Boyd, Ellison, 2007).
Si nos ceñimos a esta definición, el primer site en cumplir con estas características fue un espacio cuyo nombre hace honor a la teoría en virtud de la cual se ha desarrollado la tecnología que ha posibilitado este tipo de espacios en Internet: Sixdegrees.com. Este sitio apareció en 1997, y permitía a los internautas crear perfiles, elaborar listas de amigos, y a partir de 1998 navegar a través de las mismas. Antes de la aparición de Sixdegrees.com ya existían páginas, sobre todo orientadas a la búsqueda de pareja o a localizar antiguos compañeros de clase, en los que se podían crear perfiles. También existían espacios que permitían elaborar listas de amigos, aunque éstas sólo eran visibles para el que las confeccionaba. Pero, Sixdegrees.com es el primer espacio que combina estas dos aplicaciones: la posibilidad de crear perfiles y de elaborar y compartir listas de amigos.

La verdadera expansión de estos espacios comenzó con la aparición de sitios como Friendster o Myspace en el año 2003. Actualmente existen más de doscientas redes sociales en la Web, y algunas han superado con creces los cuarenta millones de usuarios. El éxito de estos espacios virtuales hizo que muchas empresas del sector crearan sus propias redes. Un buen ejemplo es Google, que en 2004, puso en marcha Orkut y en 2011 lanzó Google Plus.

Pero a pesar de la variedad de redes sociales, a continuación enumeramos algunas de las más populares entre los usuarios de todo el mundo:

- Facebook: esta red social comenzó a funcionar en febrero de 2004, y fue fundada por cuatro estudiantes de Harvard: Mark Zuckerberg, Eduardo Saverin, Dustin Moskovitz y Chris Hughes. Actualmente cuenta con más de 900 millones de usuarios registrados (Internet World Stats, 2012) 
y ha adoptado la forma de un boletín, muy parecido a los desarrollados por algunas universidades de todo el mundo con la finalidad de propiciar que los nuevos alumnos se conociesen entre sí.

- Myspace: esta red social fue fundada en 2003 por Tom Anderson, Chris DeWolfe y un grupo de programadores. En julio del 2005 fue adquirida por la News Corporation de Rupert Murdoch por 580 millones de dólares, un precio que superaba en un $12 \%$ al de sus acciones en bolsa. Durante los primeros años de funcionamiento era la red social más utilizada por los internautas pero actualmente está perdiendo usuarios a favor de otros espacios de similar naturaleza: los datos apuntan que actualmente recibe 90,5 millones de visitas únicas al mes (seis veces menos que Facebook) y la cifra de miembros registrados apenas superaba los 80 millones en 2012.

- Twitter: Esta plataforma fue fundada en 2006 por Jack Dorsey, Biz Stone y Evan Williams. Se trata de un espacio social basado en la filosofía del microblogging. Los usuarios se comunican entre sí a través de pequeños fragmentos de información (tweets) que no pueden superar los 140 caracteres de longitud. Este espacio ha aunado la filosofía de los blogs y la viralidad de las redes sociales. En estos momentos cuenta con más de 500 millones de usuarios registrados, de los cuales, 140 millones son usuarios activos.

- Linkedin: este espacio comenzó a funcionar en la red en 2003 de la mano de Reid Hoffman. Se trata de un red social profe- sional y actualmente posee más de 135 millones de usuarios registrados.

- Ning: es una plataforma online que permite a los usuarios crear sus propias redes sociales y unirse y participar en otras. Ning nació en 2005 de la mano de Marc Andreessen (fundador de Netscape y Opsware) y Gina Bianchini. Originariamente los usuarios podían crear sus redes de forma gratuita a cambio de aceptar publicidad, también existía la posibilidad de evitarla pagando por un servicio premium. El modelo de negocio de la red ha sido modificado recientemente y los internautas tienen que pagar por el servicio. Actualmente cuenta con 60 millones de usuarios registrados.

- Tagged: Esta red fue creada en 2004 por Greg Tseng y Johann Schleier-Smith. Permite a sus usuarios jugar, compartir información y sugerir amigos a sus contactos. Cuenta con más de 25 millones de usuarios.

- Hi5: esta red comenzó a funcionar en 2003 de la mano de Ramu Yalamanchi, y llegó a alcanzar los 70 millones de usuarios registrados, mayoritariamente originarios de América Latina. Actualmente y debido al apogeo de otras plataformas muchos de sus usuarios han migrado a otras redes sociales.

- Meetup: este espacio fue creado en 2001 por Scott Heiferman, Matt Meeker y Peter Kamali. Esta plataforma permite crear y localizar fácilmente grupos locales. El internauta introduce su código postal y puede encontrar todos los grupos existentes en esa área geográfica, además de crear sus 
propios grupos. Este espacio cuenta con 7,2 millones de usuarios registrados, que participan en alguno de los más de 79.000 grupos locales en los que aparecen representadas más de 45.000 ciudades (Meetup.com, 2012). Este espacio recibe más de10,5 millones de visitas únicas al mes.

\section{Resultados}

Se ha llevado a cabo un análisis de contenido de los espacios en Facebook de las compañías que más invierten en publicidad online en nuestro país: Telefónica, Vodafone, Orange y Renault y El Corte Inglés.

\subsection{Telefónica}

Es necesario puntualizar que esta compañía dispone de microsites específicos para los usuarios de los países en los que vende sus servicios: MoviStar Argentina, MoviStar Perú... El microsite de Telefónica España (MoviStar) poseía en el momento del análisis casi 150.000 usuarios. La estrategia de esta compañía en Facebook combina la oferta de servicios y el anuncio de novedades en los productos de la compañía con la difusión de noticias que pueden ser de interés para su público objetivo tales como la difusión de eventos deportivos y tecnológicos más orientados a un público masculino y la difusión de noticias de moda y belleza, más dirigidos al sector femenino.

Este microespacio tiene un triple objetivo, fidelizar a los clientes de la compañía, captar otros nuevos (recordemos que cuando un internauta se hace seguidor de uno de estos espacios una notificación llega a todos sus contactos, que además pueden ver las publicaciones que hace la compañía a través del muro del usuario que sirve de nexo entre la compañía y este potencial consumidor) y crear imagen de marca en la red. Es necesario resaltar que Telefónica cuenta con un community manager muy activo, lo que es una gran ayuda a la hora de atraer seguidores hacia una página. La ventaja de los medios sociales es que crean un nexo de unión entre las empresas y los consumidores al abrir una vía de comunicación directa. Por este motivo cuando los internautas interactúan con el microsite es fundamental que reciban feedback, es decir, que sientan que alguien escucha sus comentarios, sus críticas y soluciona sus problemas.

Dentro del espacio nos encontramos con diferentes secciones, entre las que cabe destacar "¿Te ayudamos?" cuyo objetivo es ofrecer un servicio de atención al cliente a través de esta red social.

La estrategia comunicativa se refuerza con una sección de fotografías donde se pueden ver imágenes de eventos patrocinados por la empresa, de los ganadores de sus concursos y promociones...

\subsection{Vodafone}

Resulta curioso comprobar que al analizar el microespacio de Vodafone España, nos encontremos con una estrategia idéntica a la de Telefónica. Este microespacio contaba en el momento de estudio con un número superior de seguidores, más de doscientos mil, por lo demás la estrategia comunicativa se vertebra sobre los mismos pilares: fidelización, captación y creación de imagen de marca, aunque no resulta tan extraño si tenemos en cuenta que ambas empresas desarrollan sus actividades en el sector productivo de las telecomunicaciones. No obstante, todas las noticias relacionadas con eventos deportivos se centran en la Fórmula 1, a diferencia de la estrategia de MoviStar, esto se debe a que es patrocinador 
oficial de la Escudería Maclaren, lo que le permite utilizar estas noticias para crear imagen de marca entre los seguidores de la página.

Igual que en el caso de MoviStar, Vodafone dispone en su espacio de Facebook de una sección de atención a sus clientes donde éstos pueden hacer preguntas que les ayuden a resolver sus dudas sobre los productos y servicios de la compañía.

También cuenta con una sección de fotografías que, replicando la estrategia de MoviStar, contiene imágenes de los eventos patrocinados por la compañía.

Además dispone de enlaces que permiten a los usuarios acceder al resto de espacios en medios sociales en los que la empresa tiene presencia.

\subsection{Orange}

El tercer microsite objeto de estudio también se corresponde con una empresa dedicada al sector de las telecomunicaciones: Orange.

La estrategia de esta empresa es idéntica a la de las dos anteriores, no obstante oferta los mismos productos y servicios. Orange España cuenta con casi 100.000 seguidores, la que menos cantidad de internautas acumula de las analizadas hasta el momento, sin embargo y dadas las características de la compañía el microsite sigue la misma estrategia que en los casos anteriores: fidelización, captación y creación de imagen de marca. Orange España utiliza el microsite para ofrecer información sobre nuevos productos y servicios y para comentar acontecimientos que puedan interesar a los usuarios, centrándose en acontecimientos deportivos y noticias de interés general.

Entre las secciones disponibles en este espacio, es necesario resaltar "Fans de nuestros fans", donde se ofrecen premios a cambio de hacerse seguidor de la página y realizar comentarios en el muro. Este espacio tiene como objetivo ampliar el número de seguidores y potenciar la interacción de los usuarios con el espacio, lo que en términos de estrategia equivale a potenciar la imagen de marca de Orange en la red.

Posee, igual que en los casos anteriormente analizados una sección de fotografías, donde muestran imágenes de los eventos patrocinados.

También cuenta con una sección denominada "Soporte y ayuda", aunque a diferencia de los casos anteriores, no supone una vía de conexión directa entre el usuario y la compañía, ya que en función de la duda que tenga el internauta se le redirige, a través de un enlace, al espacio dentro de la Web oficial de la compañía, donde el usuario puede localizar relativa a la cuestión que le preocupa.

\subsection{Renault}

El siguiente microsite analizado corresponde al fabricante de coches francés Renault. Igual que en los casos anteriores se analizó la página que la empresa ha publicado en Facebook para sus clientes españoles. El espacio contaba en el momento del análisis con casi 63.000 seguidores. Uno de los objetivos que persigue la marca es reforzar la decisión de compra de sus clientes. Esto se debe a que el producto que comercializa es un bien de consumo duradero, y que en este tipo de productos la campaña no termina cuando el cliente adquiere el bien en cuestión, sino que es necesario reforzar el comportamiento para evitar el arrepentimiento del consumidor y la aparición de sentimiento de culpa por haber adquirido el producto. 
El segundo de los objetivos es la obtención de resultados, o lo que es lo mismo la venta de vehículos.

En tercer lugar el fabricante busca crear imagen de marca. Para alcanzar estas metas la estrategia del fabricante en Facebook se centra en una comunicación basada en mostrar los productos de la empresa y sus virtudes, estrategia con la que consigue reforzar la decisión de compra de los consumidores que han adquirido un Renault además de la promoción de sus productos.

Otro de los pilares de la estrategia es la difusión de eventos, como la Fórmula 1 o el campeonato de rallies, en los que la compañía posee escuderías, lo que contribuye a generar imagen de marca y a despertar el deseo de los consumidores de poseer una vehículo cuya marca tiene representación en dichas competiciones.

En este caso nos encontramos con una estrategia comunicativa mucho más centrada en mostrar los productos que en los casos anteriormente analizados, ya que los objetivos que se persiguen con este espacio son ligeramente distintos de los anteriormente analizados.

En cuanto a las secciones disponibles en el espacio, encontramos una sección de fotografías, donde podemos localizar, casi exclusivamente, fotografías de los diferentes modelos de coches que la casa Renault tiene en el mercado, imágenes de los vehículos de sus escuderías de rally y Fórmula 1 e incluso fotografías de modelos de coches antiguos que ya no están a la venta. Apenas encontramos fotos de eventos patrocinados, aunque es normal, si recordamos que una de las estrategias de la compañía con este microespacio es la obtención de resultados a través del incremento de las ventas, en un momento que está resultado crítico para el sector del automóvil.
El resto de las secciones: "Promociones, "Renault Servicios"... poseen enlaces que redirigen al usuario hacia la Web Oficial de la compañía.

También cuenta con una sección de atención al cliente, pero a diferencia de los casos anteriormente analizados, no permite al usuario hacer consultas de forma directa sino que se le indican los teléfonos y direcciones electrónicas a los que debe dirigirse para formular sus dudas.

\subsection{El Corte Inglés}

El microsite de El Corte Inglés en Facebook contaba, en el momento del análisis, con casi 680.000 seguidores, la cifra más elevada de todos los espacios analizados en este trabajo.

En cuanto a los contenidos que la empresa comparte con sus seguidores, es necesario resaltar que se centra en mostrar productos y ofertas disponibles en sus establecimientos, aunque la estrategia comunicativa no se limita a simples anuncios sino que ofrecen videos y fotografías donde se pueden ver los productos integrados en distintos ambientes o el funcionamiento de los mismos. Además ofrecen consejos y recetas de cocina a los seguidores, para evitar que sea percibido como un espacio exclusivamente comercial. Podemos afirmar que la estrategia de esta empresa en redes sociales está orientada hacia los resultados y la fidelización de los consumidores, hipótesis que se ha visto reforzada tras el análisis de las secciones disponibles en el microsite.

Entre las secciones que ofrecen a sus seguidores cabe destacar el espacio "Top Fan", donde únicamente los seguidores de la empresa en Facebook pueden descargarse cupones con los que obtendrán descuentos de hasta el 50\% en los establecimientos de la compañía.

Otra de las secciones que destacan por su originalidad y que refuerzan la estrategia de que 
este espacio está pensado para incrementar las ventas de la empresa es "Wish List", donde los seguidores pueden confeccionar su lista de deseos eligiendo entre los productos disponibles en las tiendas de El Corte Inglés y compartirla con su red de contactos en Facebook.

En cuanto a la interacción directa con los usuarios es necesario destacar dos secciones "Servicio de Atención al Cliente" y "Valora y Opina". La primera permite a los seguidores hacer llegar preguntas, comentarios o quejas a los responsables del espacio. La segunda, muestra una lista de productos a los clientes y les piden que los valoren en función de sus gustos y preferencias, además existe un link que permite a los usuarios acceder a la tienda online de El Corte Inglés y adquirir el producto que han valorado.

El gran número de seguidores de este microespacio se debe a la gran cantidad de servicios y promociones exclusivas que ofrece a los usuarios de este espacio.

\section{Conclusiones}

El análisis de contenido pone de manifiesto que la mejor estrategia publicitaria en Social Media es la de crear microespacios corporativos en las redes sociales en las que se mueven nuestros clientes o potenciales clientes. La creación de estos espacios es gratuita para las compañías, además la viralidad de los mensajes es muy elevada, por lo que es posible hacer llegar un mensaje a una masa crítica enorme en muy pocas horas. Estos datos nos permiten verificar la primera de nuestras premisas:

H1. El nuevo escenario publicitario obliga a los anunciantes a emplear los medios sociales para alcanzar sus potenciales consumidores: el eje central de la estrategia en social media debe ser la creación y la gestión eficaz de microespacios corporativos en medios sociales.

Los resultados refuerzan la idea de que la mejor estrategia publicitaria en redes sociales pasa por crear y gestionar de forma eficaz microespacios en redes sociales. Esto se debe a que los usuarios no perciben estos sites como publicidad, acceden voluntariamente y siguen las novedades publicadas por las empresas. Además estos espacios resultan gratuitos para los anunciantes y el impacto de la marca es enorme, ya que cada vez que un internauta se hace seguidor todos los contactos reciben la noticia, por lo que la exposición a la marca es muy grande y el coste es nulo.

Además los servicios de valor añadido y las promociones exclusivas consiguen atraer usuarios hacia estos espacios, creando imagen de marca, fidelizando al consumidor y convirtiendo estas visitas en ventas online o en los establecimientos físicos. Un buen ejemplo de esta estrategia es la promoción "Top Fan" que en el momento de realizar esta investigación tenía en marcha El Corte Inglés y que ofrecía a los seguidores del microsite un descuento del 50\% en algunos productos.

Estos datos nos permiten verificar la segunda de nuestras hipótesis:

H2. Para atraer a sus consumidores y potenciales consumidores a sus espacios dentro de los social media los anunciantes deben ofrecer servicios de valor añadido a través de los mismos.

Además la gran flexibilidad de estos microespacios en redes sociales permite lanzar nuevas campañas y promociones constantemente y retirar o modificar aquellas estrategias que no ofrezcan los resultados esperados.

Por último, es necesario resaltar que los espacios corporativos en la mayoría de las redes so- 
ciales resultan gratuitos por lo que el coste de las campañas es mínimo comparado con el de las que se lanzan en los medios de masas tradiciona- les, que tampoco poseen capacidad ni la rapidez en la difusión de los contenidos de las redes sociales.

\section{Bibliografía}

Banchelli, A. (2005): "Publicidad Online: ¿Por qué es mejor invertir en blogs que en sitios con mucho tráfico?". Disponible en: http://www.masternewmedia.org/es/publicidad_ online/estrategias_de_publicidad/blogs_como_canales_publicitarios_efectivos_20051126.htm. [Fecha de consulta: 6 de abril de 2012]

Beelen, P. (2006): "Publicidad 2.0. Lo que deberían saber quienes trabajan en publicidad, marketing y medios sobre las tecnologías que están revolucionando su rubro", en: http://www.paulbeelen.com/whitepaper/Publicidad20.pdf. [Fecha de consulta: 8 de junio de 2012]

Boyd, D., Ellison, N., (2007): "Social network sites: Definition, history, and Scholarship", en Journal of ComputerMediated Communication, $n^{\circ} 13$ (1), artículo 11. Disponible en: http://jcmc.indiana.edu/voll3/issuel/boyd.ellison. html. [Fecha de consulta: 12 de mayo de 2012]

Cornellà, A.; Rucabado, S. (2006): Futuro Presente:101 Ideas-Fuerza para entender las próximas décadas. Barcelona: Ed. Deusto.

Interactive Advertising Boureau (2011): Estudio de inversión publicitaria en medios digitales. Disponible en: http://iabs-
pain.biz/estudio_inversion/Estudio_inversion_publicidad_ IAB_Spain_2011.pdf. [Fecha de consulta: 12 de mayo de 2012]

Islas, O. (2007): "Los ciberconsumidores 2.0 y la indispensable "remediación" de la Publicidad". Disponible en en: http://www.espacioblog.com/myfiles/octavioislas/intercom. pdf. [Fecha de consulta: 26 febrero de 2009]

Levine, R.; Locke, C.; Searls, D.; WeinbergeR, D. (1999): The Cluetrain Manifesto: The End of Business as Usual. Estados Unidos: Ed. Perseus Books Group.

Milgram, S. (1967): "El problema del pequeño mundo", traducción de Isidro Maya Jariego, en Araucaria, año 5, $\mathrm{n}^{\circ} 10,2^{\circ}$ trimestre de 2003.

Sola Pool, I. de, Kochen, M. (1978): "Contacts and influence", en Social Networks no 1, p. 5.

Solanas, I.,Rom, J., Sabate, J., (2007): "Un nuevo enfoque para la publicidad y el marketing. La búsqueda de la viralidad. El caso de la campaña 'Levántate ZP'”, Comunicación del IV Congreso de Comunicación y Realidad en Trípodos Extra, p. 995-1009. 